\title{
Research on New Type of Startup Power Source for Diesel Generator Sets in Alpine Region
}

\author{
Song Liu ${ }^{1, a^{*}}$, Chunming Wang ${ }^{2, b}$, Yu Zhang ${ }^{3, c}$ \\ ${ }^{1,2,3}$ PLA University of Science and Technology Nanjing, China \\ a977932805@qq.com, bnich21@126.com, ${ }^{\mathrm{c}} 3226919449 @ q q . c o m$
}

\begin{abstract}
Keywords: lead-acid battery; supercapacitor; startup power source; bidirectional converter Abstract. For the moment, the lead-acid battery is usually used as the startup power source of diesel generator sets, but in some alpine regions, the discharge capacity of the battery is obviously decreased, which affects the normal start of the diesel engine. In order to solve this problem, a new type of startup power source for diesel generator sets was designed by employing super capacitor modules. In this paper, the authors analyzed the capacitor configuration and voltage equalizing of the super capacitors, the design of the bidirectional converter, the control strategy of the whole startup power source, and other key questions. Therefore, the analysis above lays the foundation of the engineering practice for adopting supercapacitor as startup power source of diesel generator sets.
\end{abstract}

\section{Introduction}

The startup of the diesel engine is the process of starting the engine crankshaft to rotate under the action of force, until the engine runs idly. When starting a diesel engine, it is necessary to overcome the compressed gas resistance in the cylinder, as well as the friction and inertia force generated by the engine itself and its accessories. There are four commonly used methods of starting: electric start, compressed air start, auxiliary gasoline engine start. The electric power start is simple and reliable, easy to operate, easy to control, so it is widely used in all kinds of occasions. The electric starting system of diesel generator is composed of power supply, electromagnetic relay switch, starting motor, and reducer. The chemical energy of the system can be transformed into mechanical energy output, which drives the engine start up.

At present, the diesel engine uses lead-acid battery as the startup power source. However, in the condition of severe temperature and humidity changes, the discharge capacity of the battery is reduced, which makes the diesel engine cannot be normally started. In addition, the battery charging time is very long, working life is low, and when it is laid static for a long time, the electrode of regular lead-acid battery will be polarized reaction, seriously even lead to the battery scrap, which will affect the reliability of diesel engine start. Therefore, people are seeking more reliable, more efficient, more environmentally friendly starting power.

In recent years, as a new energy storage device, the supercapacitor has attracted much attention. Compared with the traditional capacitor and battery, the unique advantages of the supercapacitor are as follows: the power density is high, the charge and discharge rate is fast, the efficiency is high, the cycle life is long, the high temperature performance is good, and the environment is friendly. The characteristics of the discharge rate can be fast enough to provide sufficient power for the start of the diesel engine, to ensure the smooth start of the diesel generator set. In this paper, Cummins $250 \mathrm{~kW}$ diesel generator set was used as an example to discuss the independent application of supercapacitor in the start of diesel generator set.

\section{Selection of electrical parameters for startup system}

In order to ensure the engine startup and meet the requirements of GB/T12535, the starting torque of the starting machine must be greater than the engine resistance torque. The engine block torque mainly consists of three items: the friction resistance moment, the compression resistance moment, the moment of inertia. 
The maximum starting resistance torque to be overcome by the engine start is obtained by using the following equation.

$$
M_{C}=C V_{S}
$$

Where $M_{C}(N . m)$ is the maximum starting torque unit, $V_{S}(L)$ is the working volume of the diesel engine is generally known as the displacement of the diesel engine. The working volume of the diesel engine can be obtained by dividing the number of cylinders by the displacement of the engine .The working volume of a diesel engine can be obtained by dividing the displacement of the cylinder by the number of cylinders. , and $C$ is the ratio coefficient, in general, the diesel engine was taken from 70 to 75 at $0^{\circ} \mathrm{C}$. Cummins $250 \mathrm{~kW}$ diesel engine is used as an example (the displacement is $14 \mathrm{~L}$, the cylinder number is 6).

Diesel engine's maximum starting resistance torque:

$$
M_{C}=C V_{S}=70 * 14 / 6=163.3 N . m
$$

To successfully start the diesel engine, the engine speed must reach the minimum starting speed. Under normal circumstances, the minimum starting speed of the diesel engine is about $100 \sim 150 \mathrm{r} / \mathrm{min}$, which can be calculated by the next condition:

$$
P_{q}=1.25 M_{C} * n /(9550 \eta)=3 k W
$$

Where $P_{q}$ is the starting power, $n$ is the lowest starting speed, and the transmission efficiency $\eta$ is 0.85 in the calculation, the minimum starting speed of $n$ is $120 \mathrm{r} / \mathrm{min}$.

The maximum energy storage capacity of the capacitor is calculated by the capacitance of the capacitor and the terminal voltage of the capacitor. However, when the supercapacitor voltage drops to a certain limit of $U_{\text {min }}$, it is necessary to stop the discharge from the minimum operating voltage of the DC-DC converter which is connected with the protection of the supercapacitor. Therefore, in the actual application process, and cannot fully release the energy stored in it. If the rated voltage of a supercapacitor is $U_{\max }$, it can release the energy:

$$
E_{0}=\frac{1}{2} C\left(U_{\max }^{2}-U_{\min }^{2}\right)
$$

The energy released by the supercapacitor module can be estimated by (4). The parameters of the supercapacitor are determined according to the following 4 points:

- Starter voltage is $24 \mathrm{~V}$, supercapacitor working voltage range can set $16 \mathrm{~V}-26 \mathrm{~V}$ DC (at the same time, the energy utilization rate is $62 \%$ );

- Output power: $3 \mathrm{~kW}$ (because the starting motor required to reach the power of $3.3 \mathrm{~kW}$, and consider a certain margin);

- Output duration: $18 s$ (5 to $7 s$ each time, no more than 3 times);

- According to the working voltage range, the maximum storage energy, the duration of the load required, the capacity of the capacitor group to meet the required capacity is calculated by (5) and the required capacity is $260 \mathrm{~F}$.

$$
C=2 P^{*} t /\left(U_{\max }^{2}-U_{\min }^{2}\right)
$$

Where $P$ is $3.3 \mathrm{~kW}, t$ is $18 \mathrm{~s}, U_{\max }$ is $26 \mathrm{~V}$, and $U_{\min }$ is $16 \mathrm{~V}$.

Considering the supercapacitor in the life cycle (the environment temperature is not greater than $25^{\circ} \mathrm{C}$ under the condition, the working life is not less than 54500 hours) capacity decay of the 
maximum limit of $15 \%$, so in accordance with the engineering design margin of $15 \%$, the overall capacity of the storage system is no less than $300 F$.

The maximum operating voltage of the system is DC $26 \mathrm{~V}$, the terminal voltage of each single supercapacitor is $2.7 \mathrm{~V}$.the total capacity of the system is no less than $300 F$. According to the above technical indicators, the total capacity of the system is $300 F$, which is composed of a series of 10 capacity of $3000 F$.

Technical indicators for the supercapacitor module are shown in Table 1.

Table 1 Technology index of the supecapacitor module

\begin{tabular}{|c|c|c|c|c|}
\hline $\begin{array}{c}\text { Total Electric } \\
\text { Capacity }(F)\end{array}$ & $\begin{array}{c}\text { Capacity } \\
\text { Error }\end{array}$ & $\begin{array}{c}\text { Max Working } \\
\text { Voltage }(V)\end{array}$ & $\begin{array}{c}\text { Max DC Resistance } \\
(\mathrm{m} \Omega)\end{array}$ & $\begin{array}{c}\text { Insulation } \\
\text { Voltage }(V)\end{array}$ \\
\hline 300 & $-10 \% \sim+20 \%$ & 26 & 2.6 & 2500 \\
\hline
\end{tabular}

\section{Control model of DC-DC converter}

Because in the discharge process of the supercapacitor storage unit of the terminal voltage is gradually reduced, so, is usually a super capacitor, cannot be directly as a constant voltage source. DC-DC converter is used to ensure the output voltage is constant, and the utilization of energy storage unit is improved by using the converter.

In the diesel generator set, it is needed to charge the supercapacitor. Usually, AC or DC voltage source cannot be directly used to charge the module, also need to connect the converter, through the control of the converter to charge the supercapacitor module.

Therefore, it can be shown in Fig.1, to access a bidirectional DC-DC converter between the supercapacitor and the starting system to overcome the problem that the terminal voltage will decrease with the discharge. At the same time, it can be charged with a constant current in the charging process, and the terminal voltage of the supercapacitor reaches a certain value, and then the constant voltage charging is carried out.

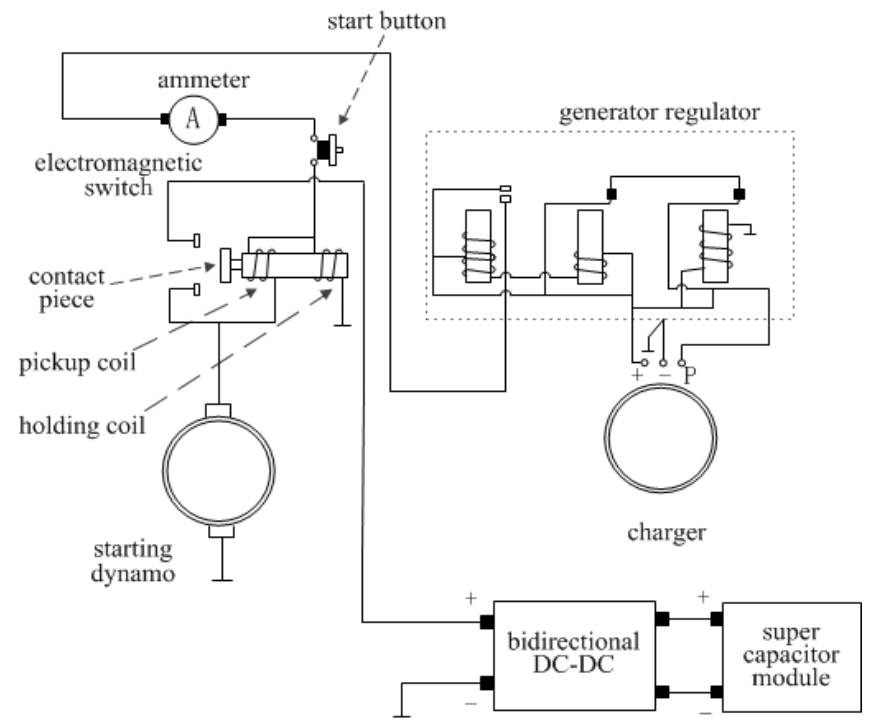

Fig. 1 Supercapacitor as starting power of starting system

The system determines the state of the diesel engine, in order to determine whether the bidirectional DC-DC converter is working in the Boost or Buck state. When the diesel engine starts, the supercapacitor is discharged, and the bidirectional DC-DC converter is working in the Boost state, and the energy stored in the supercapacitor is released into the starting system. Instead, when the boot process is finished by adjusting the bidirectional DC-DC converter to work in the Buck state, the energy generated by the charging system is transmitted to the supercapacitor. The duty cycle is controlled to adjust the output voltage of the bidirectional DC-DC converter. 
By the automatic control theory knowledge, in the working state of Buck DC-DC converter, it can make the system have a certain phase margin through PI control, and eventually make the system to achieve closed-loop stable state. Transfer function model of PI control:

$$
G_{c}(s)=K_{p}\left(1+\frac{1}{T_{i} s}\right)
$$

For a boost DC-DC converter, just add a differential link at the base of PI control to get PID control, so that the system has a certain phase margin, and eventually make the system to achieve closed-loop stable state. Transfer function model of PID control:

$$
G_{c}(s)=K_{p}\left(1+\frac{1}{T_{i} s}+T_{d} s\right)
$$

Where $G_{c}(s)$ is the transfer function of PI/PID control, the complex frequency $s$ is the independent variable; $K_{p}$ is proportional coefficient; $T_{d}$ is the differential time constant; $T i$ is the integral time constant.

As what is shown in Fig. 2, triangular wave is used as the carrier signal, and the command signal is obtained by subtracting the reference value and the actual value, the command signal and the triangular wave signal pass through the comparator to generate signal Gs1 and Gs2, which control the bidirectional DC-DC, when the current is the control variable, the PI control is used to compensate, and the voltage is the control variable, PID control is used to compensate.

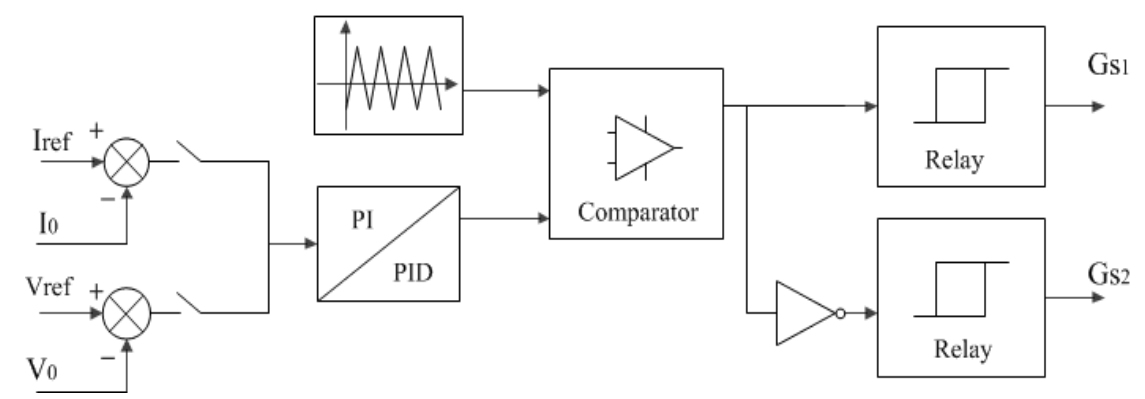

Fig.2 Control block diagram of the bidirectional DC-DC converter

\section{Simulation and analysis}

In order to verify the feasibility of the proposed scheme, the simulation model is built in MATLAB. As what is shown in Fig. 3 , the supercapacitor modules (26V, 300F) and battery (24 V, $165 \mathrm{Ah})$ are used as the power source, and the parameters of a $250 \mathrm{~kW}$ diesel generator are used as the object.

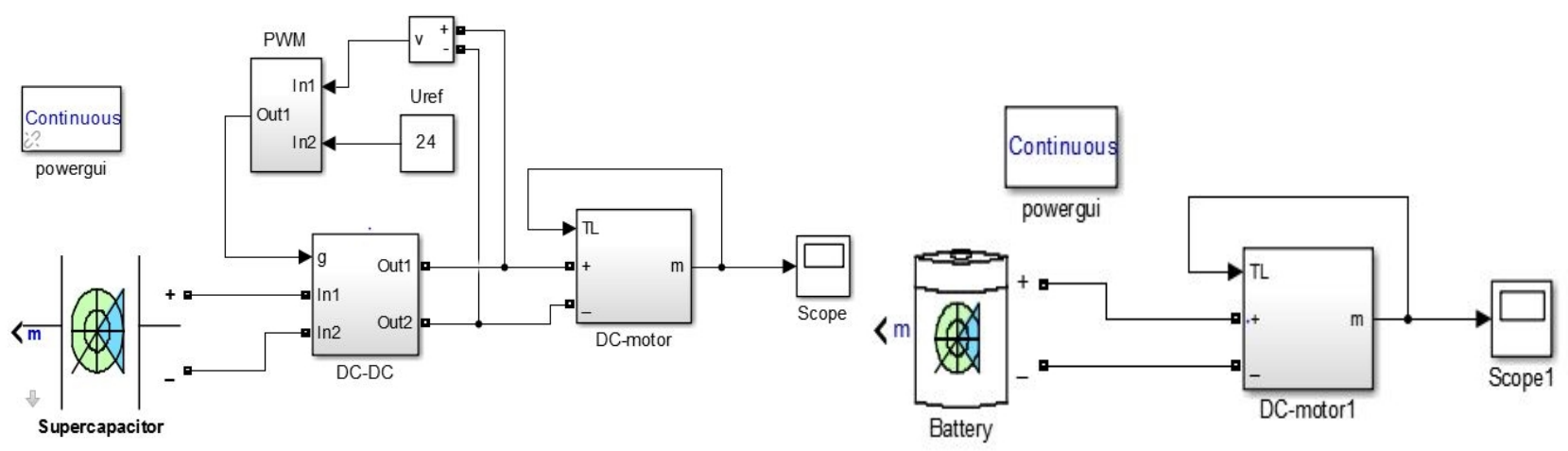

Fig. 3 The simulation model of startup system with supercapacitor and battery 
Respectively, with the super capacitor and battery as the startup power, two kinds of starting current waveforms are obtained. As shown in Fig. 4 , compared with the battery as the startup power, the peak current is raised to $1650 \mathrm{~A}$ from $1280 \mathrm{~A}$, and the stationary current of the starting process is increased from 280 A to 440 A.Lastly, the time to reach the stationary current is also about $0.15 \mathrm{~s}$ earlier than using the battery.

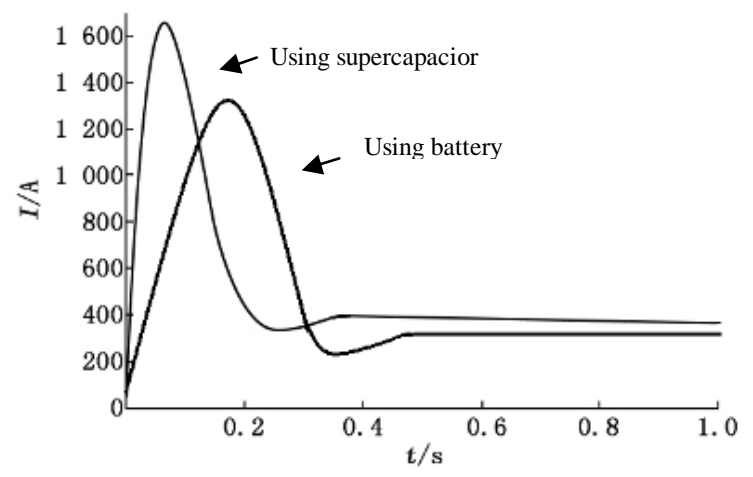

Fig. 4 Starting current of different starting power

\section{Conclusions}

By the simulation, it can be found that compared with lead-acid batteries, the resistance of supercapacitor is smaller, and therefore more current can be released instantaneously to ensure that diesel generator sets is started in a shorter period of time and to ensure the success rate each time you start. In addition, compared with lead-acid batteries, using supercapacitor as starting power has longer life, and the maintenance is more simple and convenient.

However, the use of the supercapacitor as the starting power also has its own limitations. The end voltage of the super capacitor can be reduced gradually with the discharging, or under the condition of long-term static setting, the end voltage can be obviously dropped (self-discharge phenomenon). At present, it is main to use the DC-DC converter to overcome this problem. At last, as a result of the study of the supercapacitor is still in the initial stage, the price is still high, but it can be predicted with the deepening research of the super capacitor and the application of new materials, this situation will soon be improved.

\section{References}

[1] Tang Xisheng.Research on Energy Management and Stability of Distributed Generation System with EDLC as Energy Storage [D]. Chinese Academy of sciences research graduate school, 2006. ( In Chinese )

[2] Yang Yong. Research on the matching of hydraulic transmission engineering machinery with diesel engine and starting system [D]. Xi'an, Chang'an University, 2005. ( In Chinese )

[3] Zhang Huiyan, Qi Zhiping. Design and analysis of energy storage unit of the super capacitor [J]. power supply technology, 2006,30 (4): 322-325. ( In Chinese )

[4] Ning Tao, Shen Cheng, Zhang Fucai. Application of super capacitor in low temperature start of diesel engine [J]. mobile power and vehicle, 2010 (1): 16-18. ( In Chinese )

[5] Li Kai. The use of ultra large capacity capacitor to improve the electric starting performance of diesel engine diesel generating set [J]. electric drive, 2002 (2): 37-39 ( In Chinese ) 
[6] Jun Qi.Practical technology of diesel generator set [M]. Beijing: Machinery Industry Press, 2006.07. ( In Chinese ) 